titillation of the gastric mucous membrane led to its discharge. If this be true, coagulation of the milk in the stomach is certain, no matter when or how the milk be given. lf, however, we grant the possibility of the milk running the gauntlet of gastric juice coagulation and a partial digestion, what assurance have we that it would fail to excite the pancreatic secretion, by which it would inevitably be coagulated and digested? It seems to me totally untenable to suppose that the milk can enter the absorbents directly and without change. While I gladly admit that the method of milk administration which Dr. Bulkley advocates seems to have the weight of clinical experience back of it and to be valuable, the theory as to its action seems to me out of accord with the present accepted beliefs of the best physiologists.

Dr. BULKLEY, in closing, said he was glad of the criticisms which had been made, as he believed that only by frank and full discussion could truth be brought out. He had purposely presented the paper before the Section on Physiology because he wanted the theory proposed to be scientifically considered and criticised, and he should endeavor to benefit by the re. marks made, and should study the subject still further.

But he would say that in spite of the objections that had been raised he should still adhere to theory as proposed until a better working hypothesis was obtained. Because, however the ultimate course of the milk may be considered physiologi. cally, there was somehow a vast difference, greater than he could express by words, between the behaviour of milk when taken in the ordinary way carelessly, or with food, and when administered absolutely according to the principles and meth ods laid down. This clinical difference, which he had observed for many years - from ten to twenty - and in hundreds of in stances, must have some scientific reason back of it; and, for his part, he would prefer to accept the accumulated evidence of years as demonstrating some physiologic difference than accept the statements or arguments that had been brought forward to show that the theory was untenable. Possibly the physiology was wrong -. for this is a somewhat changing science and we can not explain just how milk or indeed other aliments act under perfectly normal conditions, for it is to be remembered that experiments, on which physiology is based, always introduce an abnormal element themselves. He should, therefore, adhere to his theory as an excellent working basis, because it furnished the means of aiding in carrying out intel ligently the system or plan described, which with him and others had yielded such exceptionally beneficial results.

WHAT IS THE FOOD VALUE OF ALCOHOL?

Presented to the Section on Physiology and Dietetics, at the Forty-ninth Annual Meeting of the American Medical Association, held at Denver, Colo., June 7-10, 1898.

BY E. STUVER, M.Sc., M.D., Pн,D.

Member Colorado State Medical Society (Vice-President 1894); Rucky Mountain Inter-State Medical Association; American Medical Association; International Medical Congress, etc.

RAWLINS, WYo.

Food is described by the Standard Dictionary as: "That which is eaten or drunk, for nourishment, aliment; nutriment in the scientific sense; any substance that being taken into the body of animal or th plant, serves through organic action to build up normal structure or supply the waste of tissue, nutriment; aliment as distinguished from condiment;" and Webster gives substantially the same definition

While these definitions give what I desire to designate as the positive side of the question, there is also a negative side which should be considered in arriv. ing at a true estimate of the food value of any substance ingested by man or animals for the purpose of nutrition. By this negative side I mean that the food substance, while containing the elements necessary for tissue-building or heat-production, should not interfere with the normal organic processes of digestion, assimilation or excretion. Nor should it interfere with the normal oxygen-carrying power of the red-blood corpuscles or impair the healthy activity of the enveloping membrane which surrounds all the tissues and cells of the body, and on whose unimpaired dialyzing power the endosmosis of nutrient material and the exosmosis of broken-down, retrograde products or toxins depend. As you are all well aware, recent investigations have demonstrated the immense importance of auto-intoxication and the very serious consequences that may result from re. tained toxins or waste materials. On this subject Dr. Thomas Oliver speaks as follows: "Bouchard ${ }^{1}$ clearly indicates to us that man is constantly standing, as it were, on the brink of a precipice; he is continually on the threshold of disease. Every moment of his life he runs the risk of being overpowered by poisons generated within his system. Self-poisoning is only prevented by the activity of the excretory organs, chiefly the kidneys, and by the watchfulness of the liver, which acts the part of a sentinel to the materials brought to it by the portal vein from the alimentary canal.

In view of these facts free elimination assumes a very important place and must receive careful consideration in arriving at conclusions concerning the relative value of nutrient materials. We should inquire, not only as to the tissue-forming or heat-producing power of any particular food substance, but also ascertain how it affects digestion, assimilation and excretion, and then we will be in a position to arrive at a true estimate of its value to the system. On this basis, let us now try to ascertain the food value of alcohol. I shall confine what I have to say to ethylic alcohol $\left(\mathrm{C}_{2} \mathrm{H}_{5} \mathrm{HO}\right)$, the kind in common use.

Ever since the earliest historic times until within recent years, it has been believed that alcohol is a true tonic; that it stimulates mental activity, increases muscular force and the powers of endurance; that it enables man better to endure the rigors of extreme cold and the fervor of intense heat than he could without it; that it protects him against the invasions of disease and helps him to counteract their effects and throw them off when contracted--in short, that it elevates his thoughts, increases his powers, blunts his pains and sorrows and enhances his joys. Even twelve or fifteen years ago it was believed by many eminent authorities that pure alcohol possesses a positive food value. T. Cranstoun Charles "says: "As to the rôle played by alcohol in the economy there is still some difference of opinion, but the weight of evidence is in favor of the theory that it acts more or less as an aliment. When ingested in excess much of it traverses the system unburnt and is then found in the urine, sweat and expired air (Lallemand, Perrin, etc.); but when taken in a moderate dose the umount eliminated by the urine forms but a small proportion of that absorbed (Dupre); some even maintain that the quantity thus excreted does not amount to more than 0.7 per cent. (Thresh). The chief portion of the alcohol in the latter case, therefore, undergoes consumption in the body (Anstie, Thudicum, Schulimus, Baudet, etc.). We shall see elsewhere that a little alcohol is generated in the organism itself (Bechamp). Alcohol does not appear to increase the production of heat as a chemic agent (E. Smith), rather, in large amount, lowering temperature by checking some of the oxidation occurring in the body, particularly when abnormal, as in fevers. It also, when given in a state of health, tends to diminish muscular power, but indirectly the effect may be to increase it by improving the tone of the system

1 Bouchard: Preface to "Auto-Intoxication in Disease," page 8.

2 Elements of Physiologic and Pathologic Chemistry, 1884. 
through the appetite and digestion of food. While the carbonic acid exhaled is slightly diminished when wines and beer are taken in moderate quantity, the secretion of gastric and pancreatic juices is favored, and there is a gentle excitation of the nerve centers, and at the same time an undoubted addition made in the form of salts, fats, glycerin and albuminoids-beer being not only stimulating and tonic, but also nutritious. Indeed, of the alcoholic drinks beers occupy the first place as foods; then come cider and perry, then wines, and as they sustain and increase vital action, they must be regarded as true foods (E. Smith). According to Voit, also, alcohol must be regarded as a food, as under its influence fewer substances are decomposed in the body."

"Considered dietetically," says Pereira, "beer pos. sesses a threefold property: it quenches thirst, it stimulates, cheers, and if taken in sufficient quantity, intoxicates; and lastly, it nourishes and strengthens. The power of quenching thirst depends on the aqueous ingredient which it contains, assisted somewhat by its acidulous constituents (carbonic and acetic acids), its stimulating, cheering or intoxicating power is derived either wholly or principally from the alcohol which it contains ( 2 or 3 per cent.-in some stronger, 5 to 7 , and exceptionally 10 per cent.); lastly, its nutritive or strengthening quality is derived from sugar, dextrin and similar substances contained in it; moreover, the bitter principle of hops confers on beer tonic properties. From these combined qualities beer proves a refreshing and salubrious drink if taken in (scrupulous) moderation, and an agreeable and valu. able stimulus and support to those who have to undergo much bodily fatigue."

The above quotations are given because they tersely show the opinions held by many leading phy. sicians fifteen years ago as to the tonic and nutritive properties of alcoholic beverages. As you have doubtless perceived, however, the statements are very vague and general, and when closely scrutinized it will be observed that those beverages for which the greatest thirst-quenching, tonic and nutritive properties are claimed are the ones which contain the smallest percentuge of alcohol. This fact in itself should create the suspicion that the opinions expressed were influenced to a certain extent by inherited or acquired appetites or cravings, preconceived opinions or in extenuation of existing habits.

Lot us now glance at the physiologic effects of pure ethylic alcohol as determined by careful, accurate and painstuking investigations, with the aid of modern scientific instruments of precision. It is generally conceded that alcohol is almost immediately absorbed into the blood. Here it exerts a most pernicious effect on the red-blood corpuscles, dissolving their iron and devitalizing them (Dr. Wm. Hargreaves), arresting their development and hastening their decay (Drs. Virchow and Becker), as well as diminishing their oxygen-carrying capacity by lessening their power to absorb oxygen from the air in the lungs; by its strong affinity for water it absorbs a part of their moisture, causes them to shrink, harden and may even make them adhere in masses and so hinder their passuge through the tiny capillaries (Dr. B. W. Richardson). While in the stomach, instead of aiding digestion, as was formerly supposed, it has been shown by many careful observers that alcohol in very small amount actually retards the

\footnotetext{
3 Columbian Cyclopedia, Vol. xii.
}

digestion, especially of proteids, very much. This retardation reduces the amount of nutrient pabulum to be taken up by the blood, whose functional or selective activity as we have before seen is likewise impaired by the alcohol directly absorbed. Nor do the evils end here, because the alcohol contained in the circulating fluids on coming in contact with the enveloping membranous sheaths which surround all the tissues and cells of the body, coagulates the albumin contained in their secretions, forming a thin white film over their surfaces, thereby impairing their dialyzing power and interfering with the free ingress of nutrient material for the upbuilding and renovation of the tissues and cells as well as obstructing the free egress of retrograde products or toxins on whose prompt elimination and destruction the healthy activity of the body depends.

With the digestion retarded, the oxygen-carrying capacity of the blood lessened and the assimilation of nutrient materials as well as the elimination of retrograde products and toxins greatly impaired by the clogging of the dialyzing membranes, we would logically infer that alcohol exerts a pernicious influence on the development and functional activity of the muscular and nervous systems, besides perverting and impairing the special senses and mental activity of those who use it (effects diametrically the opposite of those produced by true foods!), and this inference or conclusion we find fully sustained by incontrovertible facts. As cogently stated by Dr. Bunge: "Thousands of experiments on large bodies of men have been made and have led to the result that, in peace or war, in every climate, in heat or cold and rain, soldiers are better able to endure the fatigues of the most exhausting marches when they are not allowed any alcohol. A similar result is observed in the case of the navies, and on thousands of commercial vessels belonging to England and America, which put to sea without a drop of alcohol. Most whalers are manned by total abstainers." Arctic explorers endure the severe cold much better when they abstain from alcohol than when they use it, even in moderation. Nor is this knowledge confined to physicians and physiologists, but the great business interests of the country are beginning so thoroughly to appreciate the fact that alcohol unfits men for doing the best work that many railroads and large manufacturing and mercantile establishments will neither employ nor retain in their employment persons addicted to the use of alcoholic beverages. That alcohol lowers muscular force and endurance is very conclusively shown by the fact that those who engage in athletio sports must stop drinking if they expect to excel. No prize fighter, ball player, oarsman or any kind of athlete can keep up drinking habits without so injuring himself in a few years that he is relegated to the rear as a back number. The careful experiments made on a number of persons by Dr. J. H. Kellog, several years ago, showed that muscular strength is diminished more than 30 per cent. by the use of alcohol, and substantially the same conclusions were reached by the elaborate experiments of Prof. C. E. Hodge, on dogs, as detailed in the Popular Science. Monthly of March and April, 1897.

\section{EFFECTS ON THE NERVOUS SYSTEM.}

But while alcohol retards digestion, impedes assimilation and excretion, reduces the oxygen-carrying power of the blood and inhibits the nutrition of the 
cells and tissues of the whole body, still it is on the brain, or indeed the whole nervous system, that its most far-reaching and malign influences are exerted.

The preliminary stimulation accelerates the heart's action, thereby increasing the amount of arterial blood sent to the brain. This produces the stage of exhilaration, excitement, brilliancy and sometimes frenzy and delirium.

"Owing to the loss of contractile power of the vessels, the increased blood-supply can not be returned to the veins from the brain with sufficient rapidity, and thus there is a block, causing impediment of the circulation, which ought to be free and unimpeded, to allow duly aërated fresh arterial supplies. This is the stage of depression, of depression and collapse, when the memory fades, speech is thickened, voluntary movement ceases, sensation is dulled and consciousness fails. This process frequently repeated sets up permanent tissue changes. The covering envelope is so thickened and otherwise injured that proper nutriment can not be conveyed to the brain, and thus that organ is badly nourished. The shape of the brain cells is altered, and the physical degradation of the cerebral substance sadly impairs the intel. lectual and moral faculties." (Dr. Norman Kerr.)

I believe the correctness of this picture can be vouched for by nearly every physician. Indeed, good illustrations of it are constantly seen, sometimes even at medical banquets. Nor is this all, for under the influence of alcohol the brain begins to think awry. It can not think straight (Dr M. S. Holbrook), and its influence on psychic processes is curious, for while it renders them much slower, the individual under its influence believes them to be much quicker than usual (Dr. Lauder Brunton). Indeed, experiments made in Heidelberg University show that the con. sumption of alcohol, whether in large or small doses, produces a tendency to paralysis of the mental faculties (Dr. Adolph Barr).

In view of these facts, I am led to believe that the so-called tonic or strengthening effects of alcohol are due more to its anesthetic and paralyzing power than to any true nutritive or tonic properties it may possess. As Dr. Kellogg has very felicitously said, alcohol is a "nerve-fooler." It makes the person who indulges in it believe his condition is very different from what it really is. If he gorges himself with too much food, alcohol may quiet the protests of his digestive organs and paralyze him into the belief that it is aiding his digestion and increasing his strength, whereas it is doing nothing of the kind.

While he may believe that his senses are keener and his powers of endurance greater, experiments with scientific instruments of precision have demonstrated that his acuity of vision is lowered, his power of hearing reduced, his sense of smell blunted and his taste so obtunded that he can swallow fiery and even caustic liquids without wincing, and his muscular strength, which he believes to be greatly augmented, is shown by the dynamometer to be materially reduced, and even his soul-stirring eloquence and poetic flights are largely discounted in the estimation of the man who has not been imbibing.

Since alcohol thus deceives the person who uses it, and as most of the beneficial results claimed to arise from its use are based on the subjective sensations of those using it, I believe we are justified, after a careful consideration of all phases of the question, after examining the arguments for and against and apply- ing to alcohol the same tests that we use in determining the utility of other substances used as food, in concluding that if it possesses any food value at all, it is to a very limited extent, and that the dangers connected with its use are so great and far-reaching that it, as every other narcotic poison, should only be used after the greatest possible precautions have been taken to guard against its untoward effects.

$$
\text { Discussion. }
$$

Dr. Stuver, in closing the discussion-I do not wish to be understood as claiming that alcohol does not have any food value. The point on which I wish to insist is, that in view of the great possibilities of doing harm, every case should be carefully investigated, and alcohol should not be prescribed in any form unless we are fully satisfled that its dangers and disadvantages will be more than compensated by its good effects in the patient's case. In short, alcohol should be used with as much care as morphin, strychnin or any other poison, and not in the careless, indiscriminate manner in which it has been in the past.

\section{ALCOHOL IN HEALTH AND DISEASE.}

Presented to the Section on Physiology and Dietetics at the Forty-ninth Annual Meeting of the American Medical Association, held at Denver, Colo., June 7-10, 1898.

BY V. D. MILLER, M.D.

NEEDHAM, MASS.

It is with some hesitancy that I present this sub. ject for your consideration, knowing, as I do, the extreme differences of opinion in regard to the effects of alcohol upon the human system, especially in disease. It is over sixty years since the composition of alcohol and its effects upon the human body have claimed the special attention of chemists, physiologists and philanthropists. Since this time very many investigations and observations have been made, and numerous important and scientific works written by investigators whose names stand high in the annals of chemistry and physiology.

Among the seventy-six known elements, there is one called carbon (chemical symbol $\mathrm{C}$ ). This element is termed an organic substance, as it occurs abundantly in living matter; it is a waste product of animal and a reconstructive product of vegetable lifethat is a food for plants and an effete matter of animals. The atomic weight of this element is 12 , and its quantivalence is $1,2,3$ or 4 , making it twelve times as heavy as our standard-hydrogen (H). It may replace atom for atom, or 1 for 2,3 or 4 . Owing to its great latitude of power it unites very readily with hydrogen, nitrogen, oxygen, sulphur (H, N, O, S) and their radicals, forming a great number of chemic compounds, among which are many of the new therapeutic remedies. We also have sugar, fat, oils, ether, chloroform and alcohols.

In forming these different classes of compounds carbon follows out definite and fixed laws from which it does not vary. Through the decomposition of vegetable matter a gas is generated known as marsh gas $\left(\mathrm{C}_{3} \mathrm{H}\right)$-methane. To this gas add $\mathrm{OH}$ and you have an alcohol. There are many gases to which if you add $\mathrm{OH}$ alcohols are formed. The alcohol $\left(\mathrm{C}_{2} \mathrm{H}_{5} \mathrm{OH}\right)$-ethyl alchol-is the one used for medicinal purposes, and is one of the best solvents we have. It readily unites with gums and resins, dissolving them; it coagulates proteids, because of its eagerness to unite with water $\left(\mathrm{H}_{2} \mathrm{O}\right)$, generating heat sufficient to cook the contained albumin. This is what takes place in the human tissues which contain albuminoid matter. The heat generated by contact of alcohol and living albuminous tissue first coagulates 